\title{
RESIDUAL STRESS CHARACTERIZATION OF THICK PECVD TEOS FILM FOR POWER MEMS APPLICATIONS
}

\author{
X. Zhang ${ }^{\dagger}$, R. Ghodssi ${ }^{\dagger \dagger}$, K-S Chen ${ }^{\dagger+\dagger}$, A. A. Ayon ${ }^{\dagger}$ and S. M. Spearing ${ }^{\dagger}$ \\ ${ }^{\dagger}$ Massachusetts Institute of Technology, Cambridge, MA 02139 \\ ${ }^{+t}$ University of Maryland, College Park, MD $20742{ }^{+t}$ National Cheng-Kung University, Taiwan 701, Taiwan
}

\section{ABSTRACT}

This paper reports residual stress characterization of thick oxide films. Engineering approaches for creating $10-20 \mu \mathrm{m}$ oxide films without cracking and wafer bow were demonstrated.

\section{INTRODUCTION}

Thick insulating films are very important for MEMS-based devices to achieve higher power levels [1]. The deleterious effects of residual stress, however, tend to increase with film thickness. In particular, excessive wafer bow and cracking can prohibit integration within a micro-device.

The present work is focused on thick oxide films fabricated using a five-station continuous plasma processing system (Concept One $^{\mathrm{TM}}$, Novellus ${ }^{\mathrm{TM}}$ Inc.) from a tetraethylorthosilicate (TEOS) precursor [2]. Conformality of TEOS in high aspect ratio features has been found to be better than that achieved by other means of growing/depositing oxide. For instance, we have successfully filled $10-30 \mu \mathrm{m}$ wide, $100-150 \mu \mathrm{m}$ deep, insulating trenches with TEOS nxide, which enables novel through-wafer interconnect schemes for igniters and temperature sensors in a micro-gas turbine device [3]. However, such thick deposited layers result in severely bowed wafers and even cracking which complicates or prevents subsequent processing.

In this paper we report a process for creating very thick (10$20 \mu \mathrm{m})$ TEOS oxide films without cracking and wafer bow. This builds on previous work by our group to develop processes for integration of thick oxide films for Power MEMS applications [45]. The motivation for this work is to elucidate the factors contributing to residual stresses in TEOS films and to optimize the deposition process so as to reduce wafer bow and to avoid film cracking.

\section{DEPOSITION AND CHARACTERIZATION}

A variety of film depositions were conducted. PECVD oxide and nitride films were both deposited at $400^{\circ} \mathrm{C}$ while LPCVD nitride was deposited at $840^{\circ} \mathrm{C}$. The deposition of PEVCD TEOS oxide was performed at low temperature $\left(350^{\circ} \mathrm{C}\right)$. The deposition rate is nominally $0.25 \mu \mathrm{m} / \mathrm{min}$ and the refractive index is 1.46 . The nominal gas flow rates are $2.3 \mathrm{ml} / \mathrm{min}$ of TEOS and $9500 \mathrm{sccm}$ of $\mathrm{O}_{2}$. The wafer-level TEOS thickness, deposited over a 4 " silicon wafer, has non-uniformity better than $1 \%$. However, there is a $3 \%$ reduction in film thickness across the wafer after densification.

The hydrogen content of TEOS films is about 4\%, as measured with Rutherford Backscattering Spectroscopy (RBS). Subsequent densification was accomplished by subjecting the films to a higher temperature for one hour while a steady $\mathrm{N}_{2}$ flow was maintained in the furnace. Table I tabulates the hydrogen content in $1 \mu \mathrm{m}$ TEOS films in six different conditions: as deposited, and after one hour densification at $700-1100^{\circ} \mathrm{C}$. The hydrogen content in TEOS films falls below $0.2 \%$ after densification at temperatures higher than $800^{\circ} \mathrm{C}$.

Curvature measurements were performed using a KLATencor ${ }^{\mathrm{TM}}$ FLX-2320 system, and the corresponding residual stress was calculated, as a function of temperature. Thermal cycling of a variety of films with a heating rate of $1^{\circ} \mathrm{C} /$ min was conducted and in situ wafer curvature was measured between room temperature and $500^{\circ} \mathrm{C}$.

Table I. Hydrogen concentration of PECVD TEOS oxide.

\begin{tabular}{|l|l|l|l|l|l|l|}
\hline $\mathrm{T}\left({ }^{\circ} \mathrm{C}\right)$ & 350 & 700 & 800 & 900 & 1000 & 1100 \\
\hline $\mathrm{H}_{2}(\%)$ & 4.00 & 0.67 & 0.13 & 0.20 & 0.17 & 0.17 \\
\hline
\end{tabular}

\section{RESULTS AND DISCUSSION}

The overall residual stress state is determined by the superposition of two primary effects. Thermal stress develops in thin films in which high temperature deposition or high temperature annealing is used, due to thermal expansion mismatch, and is usually unavoidable. Intrinsic stress is generated during the film growth process and is strongly dependent on deposition techniques and process parameters.

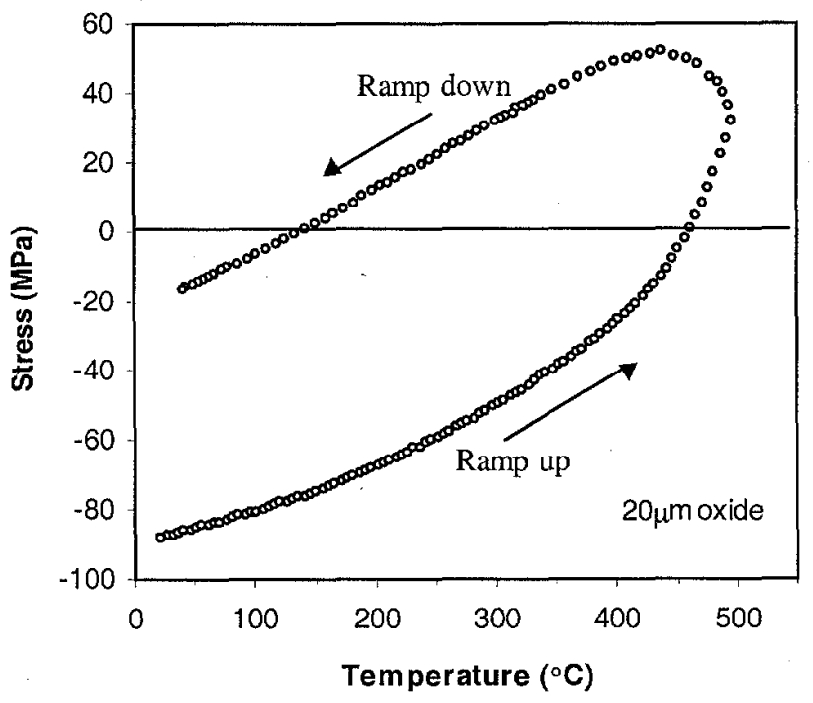

Figure 1. In situ residual stress variation of $20 \mu \mathrm{m}$ thick axide film as a function of temperature during a $500^{\circ} \mathrm{C}$ thermal cycle.

Figure 1 shows the residual stress in a $20 \mu \mathrm{m}$ thick PECVD oxide film as a function of temperature during a thermal cycle between room temperature and $500^{\circ} \mathrm{C}$. The dependence of residual stress on temperature is non-linear with significant hysteresis. Figure 2 shows the decomposition of thermal stress and intrinsic stress in an oxide film. The variation of stress with temperature is 
apparcntly duc to two superimposed effects: a linear thermal stress component, and a non-linear, irreversible intrinsic stress component. In this paper, thermal stress was estimated based on the assumption of constant material properties. For the case of oxide on silicon substrate: $\mathrm{E}_{\mathrm{f}} /\left(1-v_{\mathrm{f}}\right) \sim 70 \mathrm{GPa}, \alpha_{\mathrm{f}} \sim 0.5 \times 10^{-6} \mathrm{~K}^{-1}$, $\alpha_{\mathrm{s}} \sim 3 \times 10^{-6} \mathrm{~K}^{1}$. It is important to note that stress free temperature after thermal cycling between room temperature and $500^{\circ} \mathrm{C}$ is approximately $275^{\circ} \mathrm{C}$, lower than the oxide deposition temperature.

In situ residual stress variation with temperature in $12 \mu \mathrm{m}$ thick PECVD TEOS oxide films is given in Figure 3. Residual stress as a function of temperature in TEOS oxide films exhibited a similar non-linearity with hysteresis behavior during the thermal cycle between room temperature and $500^{\circ} \mathrm{C}$. The large hysteresis loop indicates that the intrinsic stress of TEOS oxide films was significantly reduced after thermal cycling.

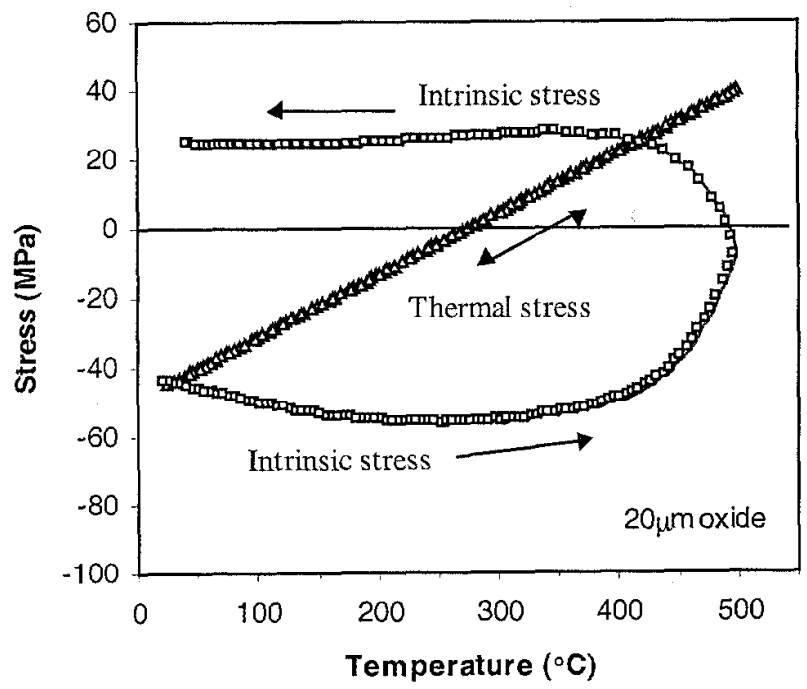

Figure 2. Decomposition of thermal stress and intrinsic stress in $20 \mathrm{um}$ thick oxide film as a function of temperature during a $500^{\circ} \mathrm{C}$ thermal cycle.

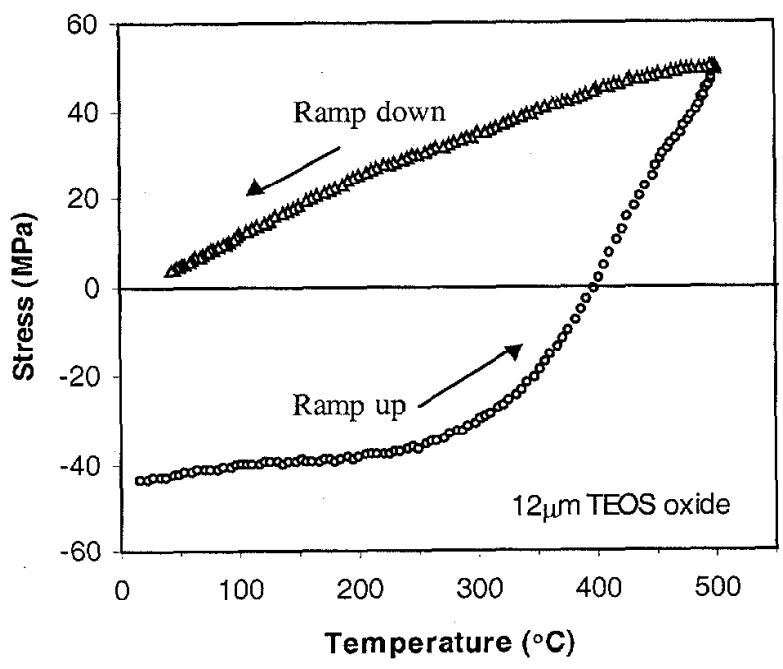

Figure 3. In situ residual stress variation of $12 \mu \mathrm{m}$ thick TEOS oxide film (on 300 um thick silicon substrate) as a function of temperature during a $500^{\circ} \mathrm{C}$ thermal cycle.
There are many mechanisms that may be responsible for the generation of intrinsic stress. Typical examples include incorporation of atoms (e.g., residual gases), chemical reactions, recrystallization, dislocation rearrangements, lattice mismatch, excess vacancy annihilation, grain boundary relaxation, and phase transformations [6]. In the present case, given that the RBS analysis of TEOS films (Table I) shows two orders of magnitude difference in hydrogen concentration before and after annealing, it is likely that the initial compressive intrinsic stress of TEOS oxide was caused by dissolved gases.

Furthermore, the densification step plays an important role in determining stress and wafer bow in TEOS oxide films. Figure 4 shows room temperature wafer bow versus TEOS film thickness, before and after $1100^{\circ} \mathrm{C}$ densification. It is seen that the wafer bow after densification is much larger than that of the as-deposited films. This is because TEOS oxide at $1100^{\circ} \mathrm{C}$ is viscoelastic and stress-free (residual stress can be relieved by material flow). As a result, the stress in TEOS oxide films becomes more compressive after high temperature densification.

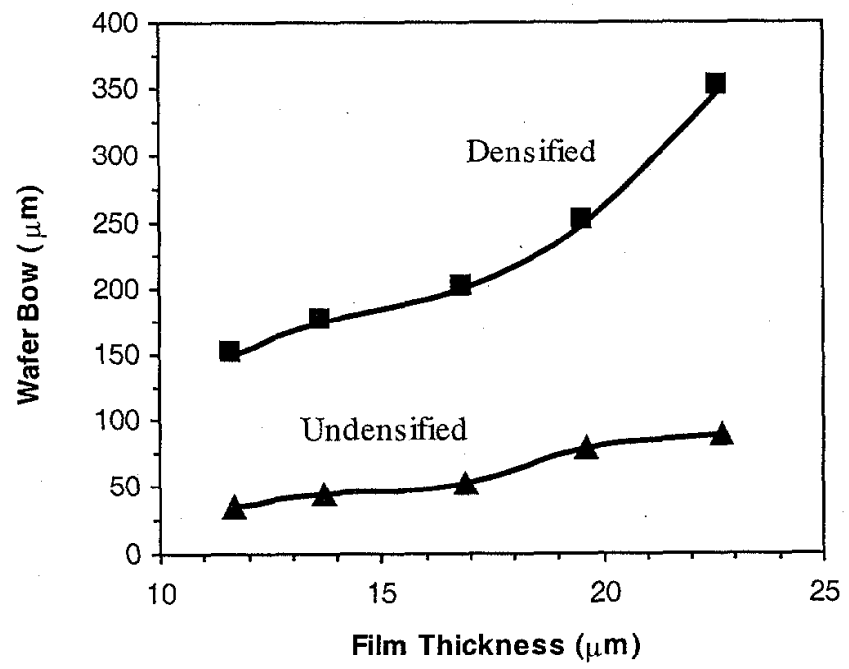

Figure 4. TEOS oxide wafer bow vs. TEOS oxide thickness before and after $1 \mathrm{hr}, 1100^{\circ} \mathrm{C}$ densification.

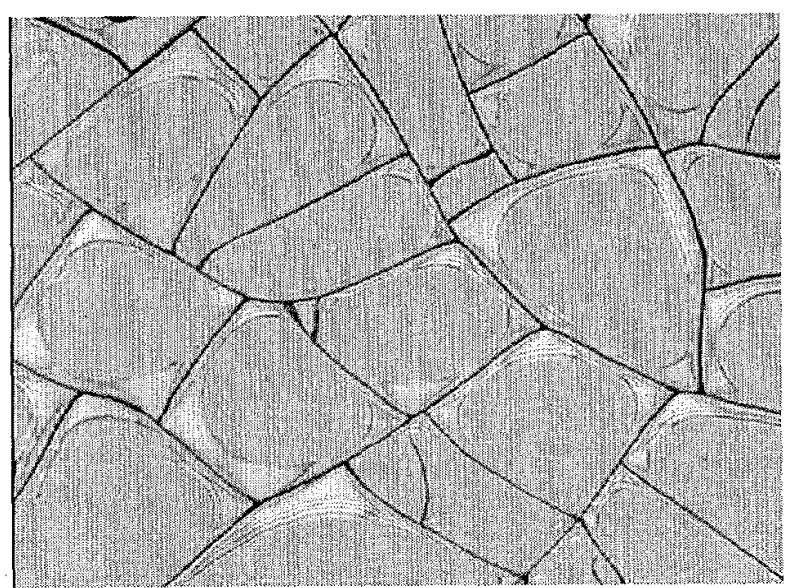

Figure 5. A cracked $25 \mu m$ thick PECVD TEOS oxide film after 24 hrs annealing at $700^{\circ} \mathrm{C}$. 
The TEOS oxide films were observed to crack after being exposed to the annealing cycle. The tendency to form cracks is a strong function of film thickness. Figure 5 shows a cracked $25 \mu \mathrm{m}$ thick TEOS film after 24 hours annealing at $700^{\circ} \mathrm{C}$. It is well known that film cracking only occurs when the film experiences a tensile stress. Since the thermal expansion coefficient of the oxide is less than that of silicon, tensile stresses will arise when the temperature is raised above the stress-free temperature. In addition, the intrinsic tensile stress generated during temperature ramp up also contributes to the failure of films. Cooling from the deposition temperature, however, leads to compressive stresses in the films and will not result in fracture.

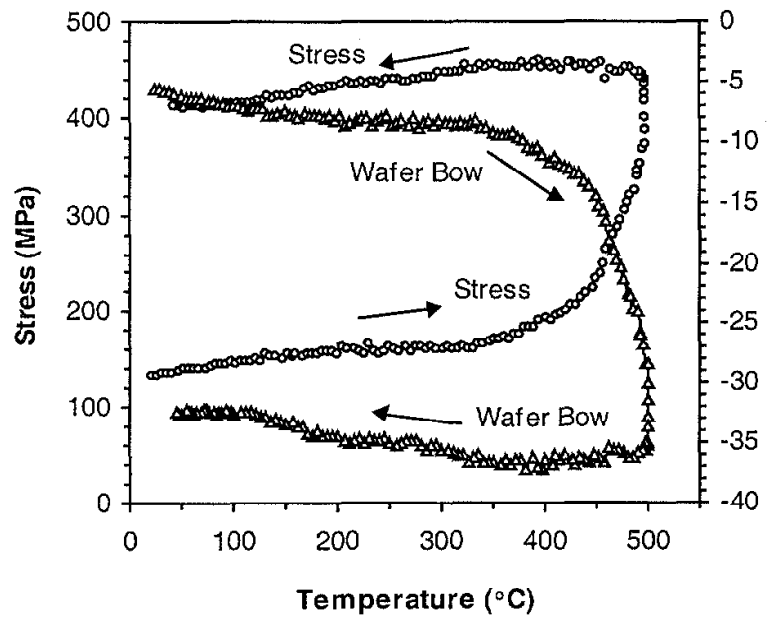

Figure 6. Residual stress and wafer bow variation with temperature in I 4 m thick PECVD-nitride films.

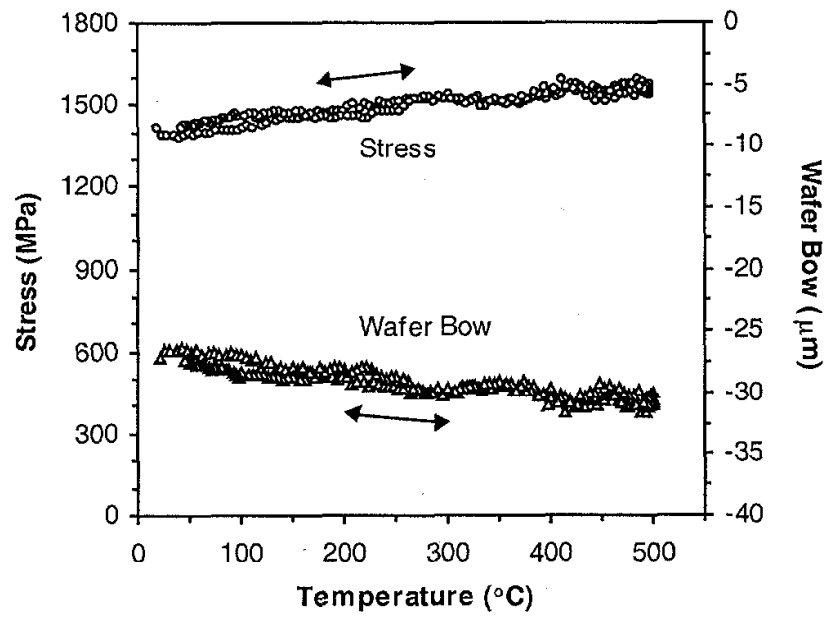

Figure 7. Residual stress and wafer bow variation with temperature in 0.25 um thick LPCVD-nitride films.

The fracture mechanics of thin films has been analyzed previously. A comprehensive summary was provided by Hutchinson and Suo [7]: The strain energy release rate for a crack propagating in a thin film is given by expressions of the form:

$$
G=Z \frac{\left(1-v_{f}\right) \sigma^{2} h_{f}}{E_{f}}
$$

Where $h_{f}, E_{f}$, and $v_{f}$ are thickness, Young's modulus, and Poisson's ratio of the film, respectively, and $\sigma$ is the stress in the film. $Z$ is a dimensionless parameter which depends on the particular cracking pattern. The crack pattern of TEOS oxide in Figure 5 corresponds to a channeling crack [7]. In this case, $Z$ takes a value of 1.976. Fracture occurs when the strain energy release rate exceeds the intrinsic fracture energy of the film material $G_{c}$. The critical temperature for fracture can be expressed as a function of film thickness, i.e.:

$$
T_{c}=T_{0}+\frac{1}{\left(\alpha_{s}-\alpha_{f}\right)} \sqrt{\frac{\left(1-v_{f}\right) G_{c}}{Z E_{f} h_{f}}}-\frac{\sigma_{I}\left(1-v_{f}\right)}{E_{f}\left(\alpha_{s}-\alpha_{f}\right)}
$$

Using the nominal material properties of the TEOS oxide, the calculated critical temperature to form cracks is about $950^{\circ} \mathrm{C}$, which is significantly higher than the observation (about $700^{\circ} \mathrm{C}$ ). This is because the contribution of intrinsic stress was not included. However, the critical temperature would be reduced if the effect of intrinsic stress is considered. For example, if the intrinsic stress was $40 \mathrm{MPa}$, the critical temperature would be reduced to $720^{\circ} \mathrm{C}$. This calculation is only approximate because no detailed material properties and intrinsic stress data are available.

The excessive wafer bow after densification causes difficulties for subsequent processing. To counteract the compressive stress inherent to the TEOS film, a highly tensile silicon nitride film was deposited prior to deposition of the thick TEOS oxide film. Residual stress and wafer bow behavior of the nitride alone under thermal cycling is shown in Figures 6 and 7. Compared to $1 \mu \mathrm{m}$ thick PECVD-nitride behavior given in Figure 6, 0.25 $\mu \mathrm{m}$ LPCVDnitride (Figure 7 ) exhibited virtually no hysterisis.

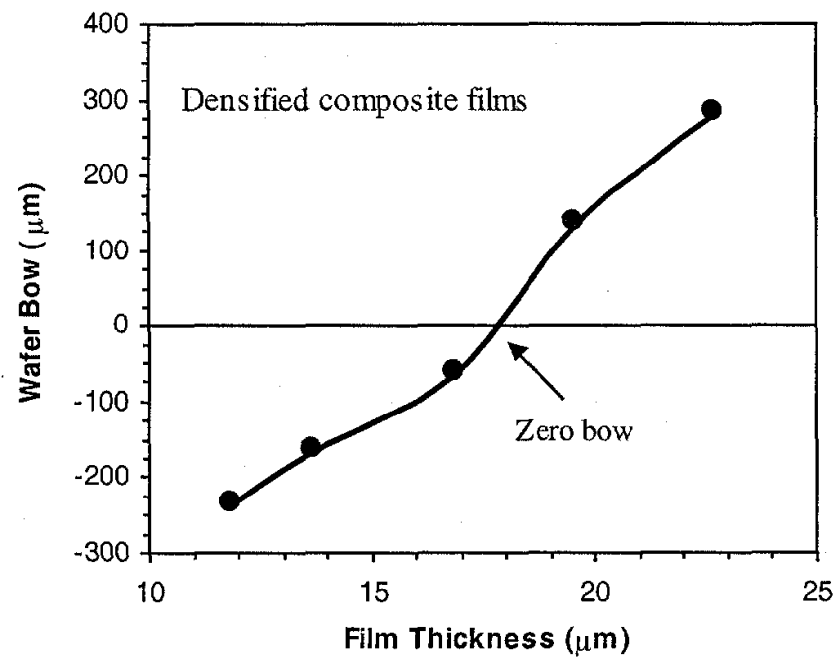

Figure 8. Wafer bow of composite films $(0.25 \mu \mathrm{m}$ thick $L P C V D$ nitride $+10-25 \mu \mathrm{m}$ thick PECVD-TEOS) vs. film thickness after $1 \mathrm{hr}$ densification at $1100^{\circ} \mathrm{C}$.

The objective of using a composite film is to introduce a film with tensile residual stress to counterbalance the effect of TEOS oxide. With proper calculation of thickness ratio and process control, it should be possible to create a wafer with low curvature. The wafer of composite films $(0.25 \mu \mathrm{m}$ LPCVD-nitride $+10-25 \mu \mathrm{m}$ PECVD-TEOS) versus film thickness after one hour, $1100^{\circ} \mathrm{C}$ densification is given in Figure 8. The composite exhibited less 
and in some case even zero wafer bow for a given film thickness. Further deformation of such composite films was not observed after they were subjected to a $500^{\circ} \mathrm{C}$ thermal cycling. The stability of the composite films under thermal cycling is illustrated by Figure 9.

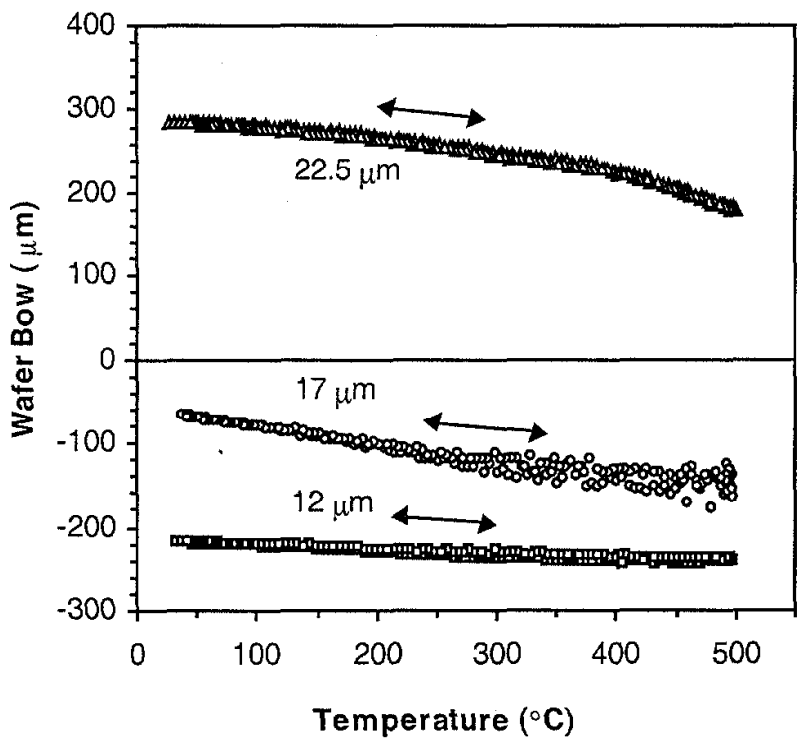

Figure 9 Stability of wafer bow of $1100^{\circ} \mathrm{C}$ densified wafers coated with composite films during a $500^{\circ} \mathrm{C}$ thermal cycle.

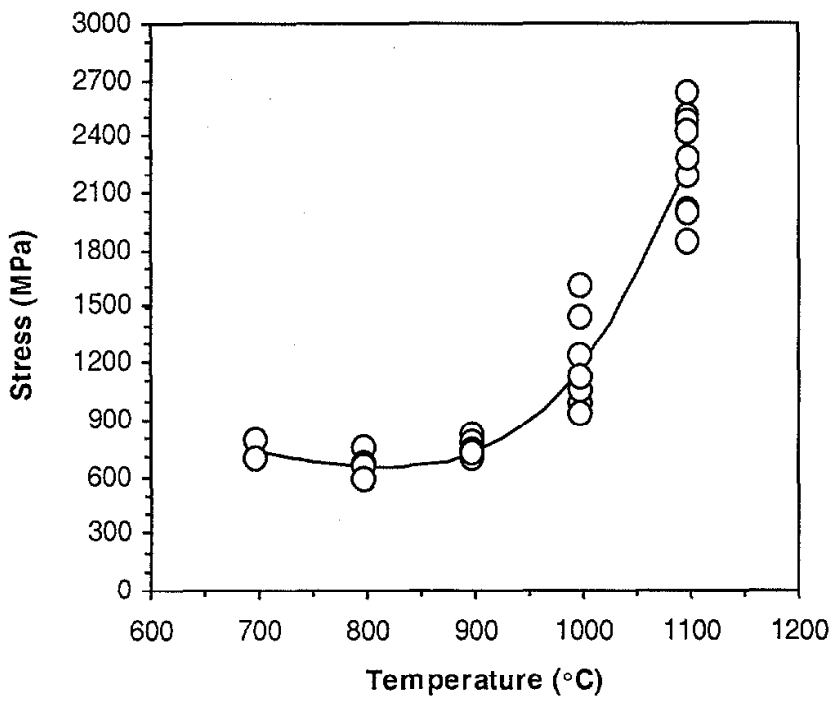

Figure 10. Residual stress variation with annealing temperature in 1 um thick PECVD-nitride films.

It should be emphasized that although there is no deflection macroscopically, the local residual stress was not reduced. As a result, this approach may still encounter problems caused by high residual stress such as delamination. Residual stress variation with anmealing temperature in $1 \mu \mathrm{m}$ thick PECVD-nitride films is given in Figure 10. The very high tensile stress $(\sim 2500 \mathrm{MPa})$ is sufficient to cause delamination of the film from the substrate after high temperature annealing, as shown in Figure 11.

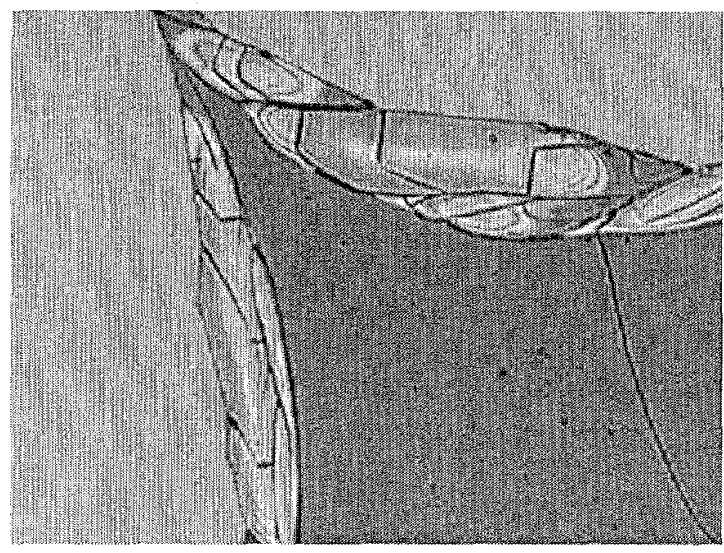

Figure 11. A delaminated $1 \mu \mathrm{m}$ PECVD-Nitride $+12 \mu \mathrm{m}$ PECVDTEOS oxide film from its silicon substrate.

\section{CONCLUSIONS}

Residual stress characterization of thick TEOS oxide films was performed. Dissolved gases were found to play an important role in governing intrinsic stress. The tendency to form cracks is a strong function of film thickness and annealing temperature. Engineering approaches for creating $10-20 \mu \mathrm{m}$ oxide films without cracking and wafer bow were demonstrated.

\section{ACKNOWLEDGEMENTS}

This work was supported by both the U.S. Army Research Office and DARPA under contract DAAH04-95-1-0093, Dr. R. Paur and Dr. R. Nowak, program managers, and National Science Council of Taiwan (NSC89-2212-E006-093). The cooperation of the staff of the Microsystems Technology Laboratories (MTL) and Technology Laboratory for Advanced Composites at MIT is also greatly appreciated.

\section{REFERENCES}

1. A. H. Epstein and S. D. Senturia, "Macro Power from Micro Machinery", Science, 276, 1211 (1997).

2. Novellus Systems Inc., 81 Visa Montana, San Jose, CA 95134.

3. A. Mehra, X. Zhang, A. A. Ayon, I. Waitz, and M. A. Schmidt, "A Through-Wafer Electrical Interconnect for Multi-Level MEMS Devices", Journal of Vacuum Science \& Technology A, in press, (2000).

4. R. Ghodssi, L. Frechetle, S. F. Nagle, X. Zhang, A. A. Ayon, S. D. Senturia, and M. A. Schmidt, "Thick Buried Oxide in Silicon (TBOS): An Integrated Fabrication Technology for Multi-Stack Wafer-Bonded MEMS Processes", Proceedings of the 1999 International Conference on Solid-State Sensors and Actuators, Sendai, Japan, June 7-10, 1999, pp. 1456-1459.

5. R. Ghodssi, X. Zhang, K-S Chen, S. M. Spearing, and M. A. Schmidt, "Residual Stress Characterization of Thick PECVD Oxide Film for MEMS Application", The $46^{\text {th }}$ International Symposium of the American Vacuum Society, Seattle, WA, 10/25$29 / 99$.

6. W. Buckel, "Internal Stresses", Journal of Vacuum Science \& Technology, 6, 606 (1969).

7. W. Hutchinson and Z. Suo, "Mixed Mode Cracking in Layered Materials", Advanced in Applied Mechanics, 29, 63 (1991). 